\title{
Pulmonary Edema and Cardiac Dysfunction Following Subarachnoid Hemorrhage
}

\author{
Nancy McLaughlin, Michel W. Bojanowski, François Girard, André Denault
}

\begin{abstract}
Background: Pulmonary edema (PE) can occur in the early or late period following subarachnoid hemorrhage (SAH). The incidence of each type of PE is unknown and the association with ventricular dysfunction, both systolic and diastolic, has not been described. Methods: Retrospective chart review of 178 consecutive patients with SAH surgically treated over a three-year period. Patients with pulmonary edema diagnosed by a radiologist were included. Early onset SAH was defined as occurring within 12 hours. Cardiac function at the time of the PE was analyzed using hemodynamic and echocardiographic criteria of systolic and diastolic dysfunction. Pulmonary edema was observed in 42 patients $(28.8 \%)$ and was more often delayed (89.4\%). Evidence of cardiac involvement during PE varied between 40 to $100 \%$. Results and conclusions: Pulmonary edema occurs in $28.8 \%$ of patients after SAH, and is most commonly delayed. Cardiac dysfunction, both systolic and diastolic, is commonly observed during SAH and could contribute to the genesis of PE after SAH.
\end{abstract}

RÉSUMÉ: GEdème pulmonaire et dysfonction cardiaque suite à une hémorragie sous-arachnoïdienne. Introduction: L'œdème pulmonaire $(\mathrm{OP})$ peut survenir précocement ou tardivement après une hémorragie sousarachnoïdienne (HSA). L'incidence de chaque type d'OP est inconnue et l'association à une dysfonction ventriculaire tant systolique que diastolique n'a jamais été décrite. Méthodes: Nous avons révisé les dossiers de 178 patients consécutifs atteints de HSA traitée par chirurgie sur une période de trois ans. Les patients ayant présenté un OP diagnostiqué par un radiologiste ont été inclus dans l'étude. L'OP était considéré comme précoce s'il survenait dans les 12 heures de l'HSA. La fonction cardiaque au moment de l'OP a été analysée au moyen des critères hémodynamiques et échocardiographiques de la dysfonction systolique et diastolique. Un OP a été observé chez 42 patients $(28,8 \%)$ et il était souvent tardif $(89,4 \%)$. La fréquence de manifestations d'atteinte cardiaque pendant l'OP variait de $40 \%$ à $100 \%$. Résultats et conclusions: Un OP survient chez 28,8\% des patients suite à une HSA et il est souvent tardif. On observe fréquemment une dysfonction cardiaque tant systolique que diastolique pendant l'HSA, ce qui pourrait contribuer à la genèse de l'OP après l'HSA.

Can. J. Neurol. Sci. 2005; 32: 178-185

Pulmonary edema (PE) is a recognized complication of major neurological events including subarachnoid hemorrhage (SAH). ${ }^{1-4}$ Usually known to occur in the hours following SAH, a delayed form has also been reported. ${ }^{3,5}$ Clinical observations and experimental studies have produced conflicting data on the mechanisms of PE following SAH. The cardiogenic component in PE's pathogenesis remains incompletely understood. Electrocardiographic modifications and pathological changes in myocardium that develop in the setting of $\mathrm{SAH}$ have been described. However, few reports have detailed hemodynamic data and wall motion abnormalities observed during episodes of PE occurring in humans. The goal of this study is to describe the incidence of early and delayed $\mathrm{PE}$ following $\mathrm{SAH}$, to demonstrate the possible existence of a cardiogenic component in both types of PE and to reveal the existence of both systolic and diastolic myocardial dysfunction. To our knowledge this is the first study to document the incidence of PE in a large population of patients with SAH and to address the issue of diastolic function in patients with PE in the setting of SAH.

\section{Population and Methods}

Retrospective chart review of all patients with aneurysmal SAH operated at the "Hôpital Notre-Dame" from April 1998 to April 2001 was performed. Initial medical management included a normal saline to maintain normovolemia, a perfusion of beta-

From the Department of Neurosurgery (NMcL, MWB), Centre Hospitalier de l'Université de Montréal (CHUM) - Hôpital Notre-Dame; Department of Anesthesiology (FG), CHUM - Hôpital Notre-Dame; Department of Anesthesiology (AD), Montreal Heart Institute; Department of Medecine - Critical Care division (AD), CHUM - Hôpital Notre-Dame, Montreal, Qc, Canada

ReCeIVEd August 14, 2003. ACCEPTED IN FINAL FORM November 10, 2004 Reprint requests to: André Denault, Department of Anesthesiology, Montreal Heart Institute, 5000 Belanger Street, Montreal, Quebec H1T 1C8, Canada. 
blockers to maintain systolic blood pressure below $150 \mathrm{~mm} \mathrm{Hg}$ and calcium channel blockers to prevent vasospasm. Chest radiographs were done routinely at admission unless the patient's clinical presentation stressed the need for an urgent surgical intervention. In these circumstances the chest X-ray was delayed after the surgery and performed in the recovery room. Postoperatively, chest radiographs were done daily while patient was intubated or during the first three postoperative days if patient was extubated rapidly after surgery. Afterwards, chest radiographs were done when clinically indicated, at the discretion of attending intensivist.

Patients were included in the study if they had diagnosis of $\mathrm{PE}$ during their hospitalization. The diagnosis of PE was based on the interpretation of the chest radiographs reviewed and confirmed by a radiologist. Clinical findings supporting the diagnostic imagery were not essential for diagnosis of PE since signs and symptoms are greatly variable and unspecific. The time period between the SAH, the PE and the surgery was noted.

Exclusion criteria were the following: 1) inadequate chest radiographs defined as poor inspiration, 2) lung infiltrates diagnosed as lung infection or aspiration, 3) patients with unstable angina or recent myocardial infarction, valvular disease, or known cardiac insufficiency. Although patients with controlled arterial hypertension, arrhythmia, or coronary artery disease may be at higher risk for cardiac decompensation in the setting of acute SAH, patients with stable conditions under medical treatment and documented normal myocardial function were not excluded from the study. If a patient presented more than one episode of PE, each episode was studied separately. Early onset has been defined as PE occurring in the first 12 hours after SAH.

Myocardial function was assessed using hemodynamic criteria suggestive of systolic or diastolic dysfunction. The following variables were defined as abnormal based on established criteria: ${ }^{6}$ central venous pressure (CVP) $>15 \mathrm{~mm} \mathrm{Hg}$, pulmonary capillary wedge pressure (PCWP) $>15 \mathrm{~mm} \mathrm{Hg}$, mean pulmonary arterial pressure (MPAP) $>25 \mathrm{~mm} \mathrm{Hg}$, the ratio of mean arterial pressure (MAP) on MPAP $<4,8$ (normal value $>4$ ) expiratory end tidal $\mathrm{CO}_{2}\left(\mathrm{ETCO}_{2}\right)<25 \mathrm{~mm} \mathrm{Hg}$, cardiac index (CI) $<2.5 \mathrm{~L} / \mathrm{min} / \mathrm{m}^{2}$ or reduction of $40 \%$ or more of the initial value. All intraoperative and postoperative hemodynamic evaluations were reviewed by an intensivist and cardiac anesthesiologist expert and with Board Certification in perioperative echocardiography. Data were collected within a six-hour period before or after initial chest radiograph with signs of PE. The echocardiographic exams were performed either by an anesthesiologist expert or a cardiologist expert with National Board Certification. Systolic dysfunction was evaluated using two-dimensional (2D) observations of wall motion abnormalities classified as normal, akinetic, hypokinetic or dyskinetic. ${ }^{9}$ The ejection fraction was estimated using fractional area change measured using a transgastric mid-papillary view. ${ }^{10}$ No contrast agents were necessary to evaluate ventricular function. This measure has been validated. ${ }^{11,12}$ Diastolic function was evaluated according to the Canadian consensus. ${ }^{12}$

\section{RESUlts}

A total of 385 consecutive patients admitted between April 1998 and April 2001 with confirmed SAH either by lumbar puncture or positive computed tomogram scan were retro- spectively studied. Among these, 296 cases were secondary to ruptured aneurysms: 118 underwent endovascular treatments and 178 underwent surgical interventions. Forty-two patients (28.8\%) were included in the present study for a total of 47 episodes of PE (Figure 1). Demographic variables are presented in Table 1.

Delay between SAH and PE onset are presented in Table 2. Five cases had an early onset $(10.6 \%)$ and 42 a delayed onset $(89.4 \%)$. Delay between SAH and aneurysm surgery was $<24$ hours in 29 cases (62\%), 24 to 48 hours in nine cases (19\%), 48 to 72 hours in one case (2\%), 72 to 96 hours in four cases $(8.5 \%)$. In four cases $(8.5 \%)$ delay was more than four days due to delayed patient consultation or delayed hospital transfer.

In the intraoperative setting, using the hemodynamic criteria, abnormal values were observed between $58.3 \%$ and $100 \%$ (Table 3 ). From the $47 \mathrm{PE}$ episodes studied, 43 (91.5\%) satisfied at least one criterion and $24(51.1 \%)$ satisfied at least two criteria. In the four cases not having satisfied any criterion, only the CVP and $\mathrm{ETCO}_{2}$ were available in the charts. At the moment of radiographic diagnosis of $\mathrm{PE}$, abnormal values were observed between $50 \%$ and $94.7 \%$ (Table 4), at least one criterion was satisfied in $27(57.5 \%)$ cases and two or more were satisfied in $16(34.0 \%)$ cases. In the 20 cases not having satisfied a criterion, the CVP was the only available data in 13 cases and no data was available in seven cases.

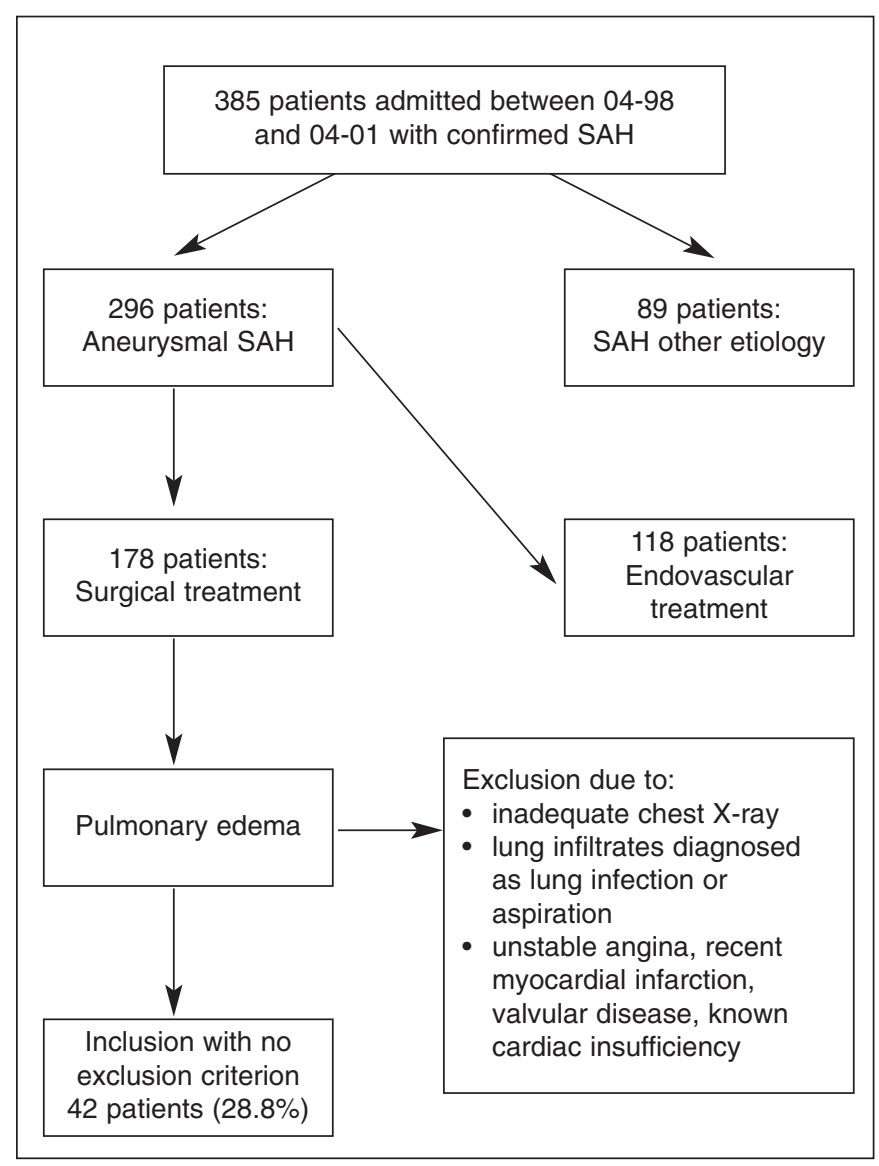

Figure 1: Algorithm for patients' distribution. 
Table 1: Demographic variables.

\begin{tabular}{ll}
\hline Characteristics & \\
Sex & M: 14 \\
& F: 28 \\
Age & Mean 51.8 \\
& Range: 33-79 \\
Coronary artery disease & 2 \\
Systemic hypertension & 15 \\
Arrhythmia & 1 \\
Smoking & 20 \\
Hunt \& Hess grade & Good (grades 1-2): 13 \\
& Fair (grade 3): 13 \\
& Poor (grades 4-5): 16
\end{tabular}

Table 2: Delay between subarachnoid hemorrhage and pulmonary edema onset.

\begin{tabular}{lc}
\hline $\begin{array}{l}\text { Delay between SAH and PE onset } \\
\text { (in days) }\end{array}$ & Number of episodes \\
{$[0-0.5[$} & 5 \\
{$[0.5-1[$} & 1 \\
{$[1-2[$} & 10 \\
{$[2-3[$} & 8 \\
[3-4[ & 11 \\
[4-5[ & 6 \\
5 and more & 6
\end{tabular}

Abbreviations: $\mathrm{SAH}=$ subarachnoid hemorrhage; $\mathrm{PE}=$ pulmonary edema.

Table 3: Intraoperative hemodynamic evaluation.

\begin{tabular}{lccr}
\hline Abnormal variable & $\begin{array}{c}\text { Data available } \\
\text { (Number of cases) }\end{array}$ & $\begin{array}{c}\text { Criterion satisfied } \\
\text { (Number of cases) }\end{array}$ & $\%$ \\
CVP $>15 \mathrm{~mm} \mathrm{Hg}$ & 24 & 14 & 58.3 \\
$\mathrm{PCWP}>15 \mathrm{~mm} \mathrm{Hg}$ & 4 & 3 & 75.0 \\
$\mathrm{MPAP}>25 \mathrm{~mm} \mathrm{Hg}$ & 24 & 14 & 58.3 \\
Ratio MAP/MPAP $<4$ & 24 & 24 & 100.0 \\
$\mathrm{EtCO}_{2}<25 \mathrm{~mm} \mathrm{Hg}$ & 47 & 28 & 59.6 \\
\end{tabular}

Abbreviations: $\mathrm{CVP}=$ central venous pressure; $\mathrm{PCWP}=$ pulmonary capillary wedge pressure; $\mathrm{MPAP}=$ mean pulmonary artery pressure; $\mathrm{MAP}=$ mean arterial pressure; $\mathrm{EtCO}_{2}=$ End-tidal carbon dioxide.

In some patients, the hemodynamic findings were by themselves diagnostic of myocardial involvement. In other cases, the anesthesiologist or intensivist requested that an echocardiographic exam be done to confirm the suspected cardiac dysfunction. An echocardiographic exam was performed in 20 cases of PE. Eight patients (40\%) showed a local and/or global diminished left ventricular systolic function. Of the two exams that were done before pulmonary deterioration, one showed apical hypokinesis. One case that was investigated the following day of PE diagnosis had hypokinetic and akinetic segments. Cases investigated more than two days after onset of pulmonary deterioration showed no wall motion abnormality. Left ventricular ejection fraction was normal $(>50 \%)$ in three cases that had segmental hypokinesis and one case with diffuse hypokinesis. Left ventricular ejection fraction was mildly (40 to $50 \%$ ) diminished in one case with hypokinetic and akinetic segments and severely $(<30 \%)$ diminished in one case with hypokinetic segments and another with akinetic segments. In one case, hypokinesis was found on echocardiography but left ventricular ejection fraction was not reported during the exam.

An example of a patient with PE who developed hemodynamic instability intraoperatively is shown in Figure 2. This was a 37-year-old woman with no past medical history of cardiac disease who presented with a SAH. The CT scan done at her arrival showed massive SAH with intraventricular flooding and $\mathrm{PE}$ was present on the chest radiograph performed at admission. No cardiomegaly was noted. The intraoperative hemodynamic tracing showed a heart rate from 88 to 96 beats/min, systolic and diastolic arterial pressure from 94 to 104 and 51 to $59 \mathrm{~mm} \mathrm{Hg}$, elevated systolic and diastolic pulmonary artery pressure with a mean value above $25 \mathrm{~mm} \mathrm{Hg}$ and a ratio of MAP to MPAP of 1.9. This was associated with a V wave on the pulmonary artery tracing. With transesophageal echocardiography, there was no significant mitral regurgitation with color Doppler. On pulse wave Doppler, a significant E $(90 \mathrm{~cm} / \mathrm{sec})$ to A $(30 \mathrm{~cm} / \mathrm{sec})$ ratio and a short deceleration time $(140 \mathrm{msec})$ was present, consistent with abnormal diastolic function. In addition, she had severe apical akinesis and diffuse mid-papillary hypokinesis.

\section{Discussion}

It has been previously described that PE most often developed within minutes to a few hours after an acute central nervous system insult. ${ }^{1,3,5,13-15}$ However PE may have a delayed onset and develop within the first few days of the insult. ${ }^{3,5,16}$ Our results support the existence of a more common delayed type of PE with an incidence of $89 \%$.

Table 4: Hemodynamic evaluation at the moment of radiographic diagnosis of pulmonary edema.

\begin{tabular}{lccc}
\hline Abnormal variable & $\begin{array}{c}\text { Data available } \\
\text { (Number of cases) }\end{array}$ & $\begin{array}{c}\text { Criterion satisfied } \\
\text { (Number of cases) }\end{array}$ & $\%$ \\
$\mathrm{CVP}>15 \mathrm{~mm} \mathrm{Hg}$ & 40 & 21 & 52.5 \\
$\mathrm{PCWP}>15 \mathrm{~mm} \mathrm{Hg}$ & 12 & 10 & 83.3 \\
$\mathrm{MPAP}>25 \mathrm{~mm} \mathrm{Hg}$ & 19 & 13 & 68.4 \\
$\mathrm{R}$ atio MAP/MPAP $<4$ & 19 & 18 & 94.7 \\
$\mathrm{CI}<2.5 \mathrm{~L} / \mathrm{min} / \mathrm{m}^{2}$ or & & & \\
$\begin{array}{l}\text { reduction of } 40 \% \text { or more } \\
\text { from initial value }\end{array}$ & 8 & 4 & 50.0 \\
\hline
\end{tabular}

Abbreviations: $\mathrm{CVP}=$ central venous pressure; $\mathrm{PCWP}=$ pulmonary capillary wedge pressure; $\mathrm{MPAP}=$ mean pulmonary artery pressure; $\mathrm{MAP}=$ mean arterial pressure; $\mathrm{CI}=$ cardiac index. 


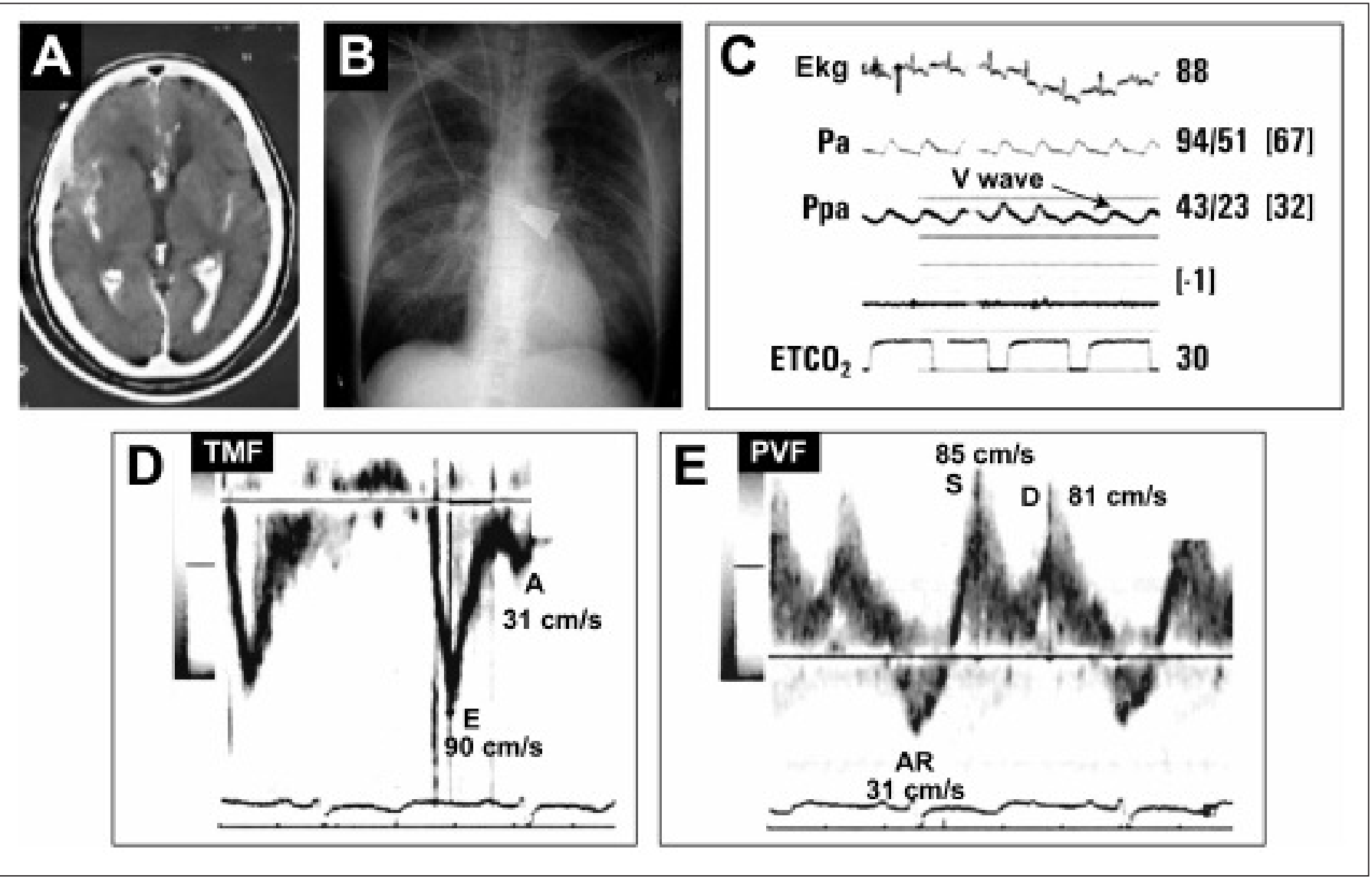

Figure 2: A 37-year-old woman with subarachnoid hemorrhage. The patient's head CT-scan showed intraventricular bleeding (A) and pulmonary edema is seen on the chest radiograph $(B)$. The hemodynamic tracing shows a heart rate of 88 beats/min, systolic and diastolic arterial pressure of 94 and $51 \mathrm{~mm} \mathrm{Hg}$, systolic and diastolic pulmonary artery pressure of 43 and $23 \mathrm{~mm} \mathrm{Hg}$ with a prominent V wave (C). Transmitral flow Doppler velocities of the mitral valve inflow reveals a high E/A ratio $(D)$ and the systolic " $S$ " to diastolic " $D$ " ratio of the pulmonary venous flow is close to $1(E)$. These features are consistent with abnormal diastolic function and elevated filling pressure. There was no significant mitral regurgitation with color Doppler (data not shown). (AR: atrial reversal, EKG: electrocardiogram, ETCO ${ }_{2}$ : end-tidal carbon dioxide, Pa: arterial pressure, Ppa: pulmonary artery pressure).

The mechanisms of pulmonary edema occurring after a central nervous system lesion are partially understood. Four primary forces determine fluid movement through the capillary membrane: capillary pressure, interstitial fluid pressure, plasma colloid osmotic pressure, and interstitial fluid colloid osmotic pressure. Controversial evidence in current literature brought authors to believe that the PE found in these patients may be due to a spectrum of hemodynamic and permeability mechanisms (Figure 3). The term neurohemodynamic pulmonary edema has been proposed. ${ }^{17}$ This is supported by various authors that suggest simultaneous hydrostatic and permeability mechanisms..$^{3,4,18-21}$ A summary of the various mechanisms proposed in case reports and retrospective studies from human literature is presented in Table 5.

Many case reports supporting the hydrostatic mechanism have been published. However, only a few retrospective studies supporting or refuting this hypothesis can be found in the literature. Our observations show that a significant proportion of patients with $\mathrm{PE}$ in the setting of SAH have an abnormal hemodynamic profile suggesting myocardial dysfunction which might contribute to a raised hydrostatic pressure.

Several authors have studied the various effects SAH might have on the myocardium. This represents a spectrum of disease from cellular changes to increased enzymes such as Creatine Kinase isoenzyme Muscle-Brain (CK-MB) and troponin, electrocardiographic changes, hemodynamic and echocardiographic abnormalities. Evidence supports catecholamine surge mediated by the sympathetic system as primary contributor to myocardial damage. ${ }^{19,22-26}$ In several studies, all myocardial cells had changes in their ultra-structure varying from mild cell disruption to cell death. ${ }^{24,27-29}$ This cellular disruption supports the idea that a certain quantity of myocardial cell abnormality is required for a clinical manifestation to occur.

This cardiac multifocal myocytolysis is supported by numerous reports of elevated CK-MB concentrations measured in SAH patients. ${ }^{22,23,25,30-32}$ The CK-MB release was found to increase progressively as left ventricular performance decreased. ${ }^{31}$ The incidence of myocardial damage is further 


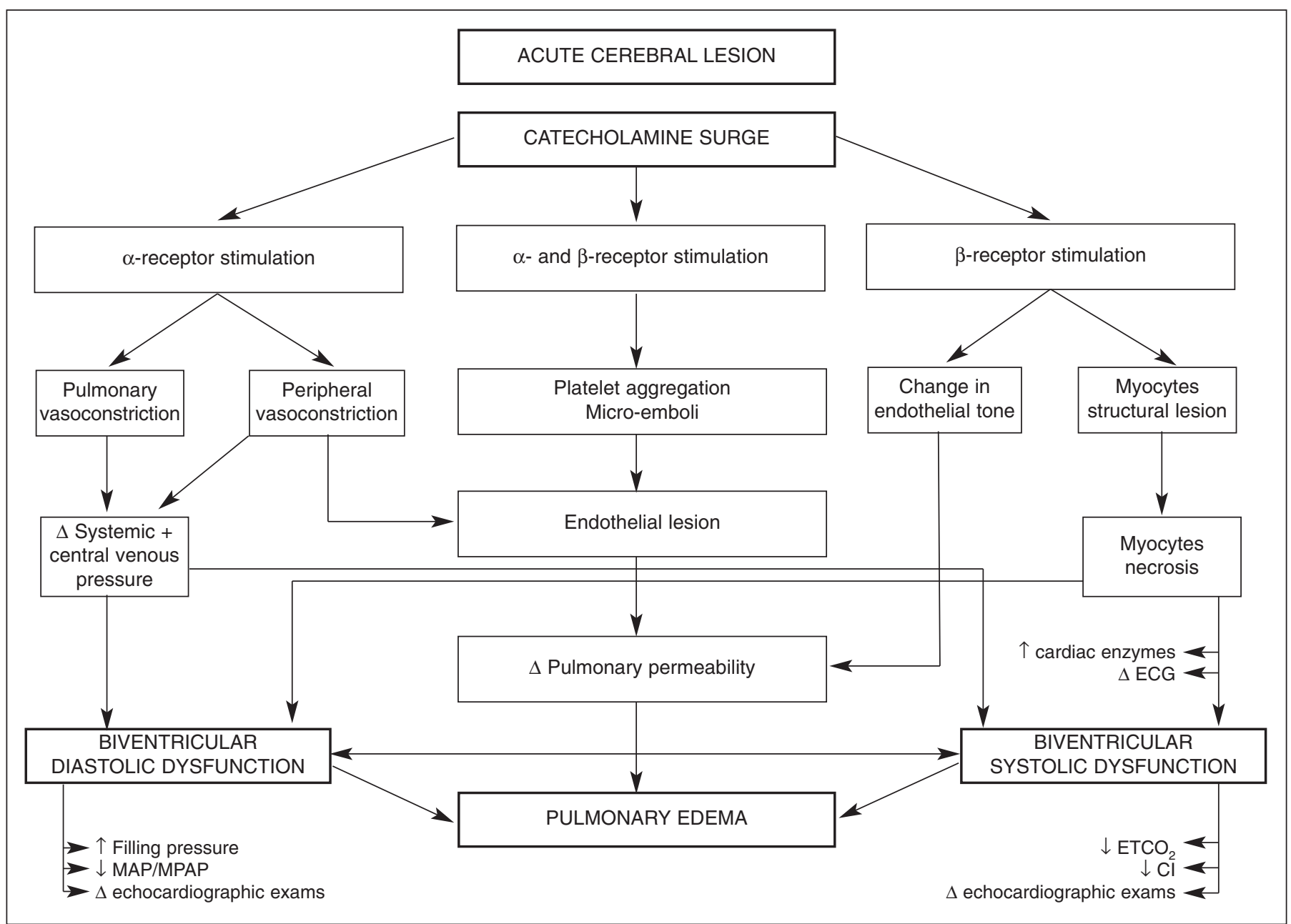

Figure 3: Pathophysiology of neurogenic pulmonary edema. (Abbreviations: CI: cardiac index, ETCO2: end-tidal carbon dioxide, MAP/MPAP: ratio of mean arterial pressure to mean pulmonary arterial pressure (normal value $>4$ )).

supported by measurement of troponin I that has been found to reveal a higher incidence of myocardial injury than predicted by $\mathrm{CK}-\mathrm{MB}$ in SAH patients and troponin I would be associated with a higher incidence of myocardial dysfunction. ${ }^{33}$

Electrocardiographic modifications are accounted for by activation of neural pathways and also by the presence of structural lesions. ${ }^{25,27,30,32}$ Electrocardiographic abnormalities in patients with $\mathrm{SAH}$ are not specific and often transient. Echocardiographic studies have found wall motion abnormalities in $9 \%$ to $23 \%$ of $\mathrm{SAH}$ patients with electrocardiographic abnormalities. ${ }^{34}$ These wall motion abnormalities are associated with $\mathrm{T}$ wave inversion and severe QTc prolongation, borderline CK-MB elevation ( $2 \%$ to $5 \%$ ), and poor neurological grade. ${ }^{30-}$ ${ }^{32,34}$ Studies exploring left ventricular function during $\mathrm{SAH}$ are summarized in Table 6.

Our observations suggest that a cardiogenic component is present in a significant proportion of patients with $\mathrm{PE}$ following SAH. Abnormal hemodynamic variables obtained in this study were suggestive of myocardial dysfunction and confirmed by the echocardiographic findings.

Although we observed mostly systolic dysfunction, diastolic dysfunction is commonly present in patients with systolic dysfunction. So far, the presence of diastolic dysfunction has not been reported as a potential mechanism in PE associated with SAH. However it has been observed in up to $59 \%$ of hemodynamically unstable patients in the intensive care unit after cardiac surgery ${ }^{35}$ and in unstable patients following SAH in whom transesophageal echocardiography was performed during episodes of hemodynamic instability. The extent to which diastolic dysfunction alone could contribute to PE in SAH is unknown.

There is growing interest in the appreciation of diastolic function. This interest is in part due to a widespread use of echocardiography which enables the noninvasive diagnosis of diastolic dysfunction. Diastolic dysfunction is likely to be an important contributor in $>30 \%$ to $50 \%$ of patients presenting with PE. ${ }^{36-38}$ It has been recognized to adversely affect outcome in patients with left ventricular ${ }^{39-42}$ and right ventricular systolic dysfunction $^{43}$ and even in patients without left ventricular systolic dysfunction. ${ }^{44}$

The recognition of myocardial dysfunction in SAH patients might have important clinical significance. The existence of segmental or global wall motion abnormalities could facilitate the formation of thrombi that can embolize distally. Aggressive 
Table 5: Summary of human studies concerning mechanisms contributing to pulmonary edema in patients with subarachnoid hemorrhage.

\begin{tabular}{lccc}
\hline Authors & $\begin{array}{c}\text { Type of } \\
\text { study }\end{array}$ & $\begin{array}{c}\text { Number } \\
\text { of patients }\end{array}$ & $\begin{array}{c}\text { Principal mechanism } \\
\text { proposed }^{1}\end{array}$ \\
Ducker $1968^{46}$ & $\mathrm{CR}$ & 11 & $\mathrm{NM}$ \\
Ciongoli $1972^{47}$ & $\mathrm{CR}$ & 3 & $\mathrm{NM}$ \\
Harari $1976^{16}$ & $\mathrm{CR}$ & 5 & $\mathrm{P}$ \\
Kosnik $1977^{48}$ & $\mathrm{CR}$ & 6 & $\mathrm{HP}$ \\
Wray $1978^{14}$ & $\mathrm{CR}$ & 1 & $\mathrm{HP}+\mathrm{P}$ \\
Carlson $1979^{15}$ & $\mathrm{CR}$ & 1 & $\mathrm{HP}$ \\
Fein $1979^{49}$ & $\mathrm{RS}$ & 24 & $\mathrm{P}$ \\
Eggleston $1982^{50}$ & $\mathrm{CR}$ & 3 & $\mathrm{NM}$ \\
Fein $1982^{2}$ & $\mathrm{CR}$ & 24 & $\mathrm{P}$ \\
Langerkranser $1982^{51}$ & $\mathrm{CR}$ & 5 & $\mathrm{HP}$ \\
Melon $1985^{52}$ & $\mathrm{CR}$ & 2 & $\mathrm{P}$ \\
Schell $1987^{53}$ & $\mathrm{CR}$ & 1 & $\mathrm{HP}$ \\
Pender $1992^{5}$ & $\mathrm{CR}$ & 4 & $\mathrm{HP}+\mathrm{P}$ \\
Handlin $1993^{22}$ & $\mathrm{CR}$ & 1 & $\mathrm{HP}$ \\
Mayer $1994^{25}$ & $\mathrm{CR}$ & 5 & $\mathrm{HP}$ \\
Deehan $1996^{54}$ & $\mathrm{RS}$ & 20 & $\mathrm{HP}$ \\
Smith $1997^{55}$ & $\mathrm{RS}$ & 12 & $\mathrm{HP}$ \\
& & &
\end{tabular}

Abbreviations: $\mathrm{CR}=$ case report; $\mathrm{RS}=$ retrospective study; ${ }^{1} \mathrm{HP}=$ raised hydrostatic pressure; $\mathrm{P}=$ increased permeability; $\mathrm{NM}=$ no mechanism proposed. hypertension-hypervolemia-hemodilution therapy might facilitate apparition of PE because patients with ventricular dysfunction do not tolerate increases in afterload. Such patients could be candidates for the use of inotropes such as dobutamine to improve cerebral perfusion. In these patients, intensive hemodynamic monitoring may be sought but $2 \mathrm{D}$ echocardiography should be obtained to evaluate both ventricular systolic and diastolic function.

There are some limitations to the present study. This study was retrospective and the selection and use of the various monitoring devices were not controlled for and could be subject to bias. Consequently, the real incidence of a cardiogenic component in PE occurring in SAH setting could be higher than reported if for instance $2 \mathrm{D}$ echocardiography was performed in all patients. The cardiac enzymes such as troponin are not measured routinely after SAH. There is also a time delay in the apparition of PE and cardiac dysfunction following SAH. Earlier echocardiographic exam could have detected a higher incidence of cardiac dysfunction.

The pulmonary artery catheter was not used in all patients. The routine use of this catheter in noncardiac surgery is controversial $^{45}$ and therefore used differently among clinicians. The timing of the echocardiographic exam was not controlled. Due to the reversibility of myocardial dysfunction, some exams performed later after the initial ictus might have shown normal myocardial function. We have seen patients with severe myocardial function in the operating room with significant improvement within 24 hours and complete normalization a week after hospitalization. Such reversibility of the echocardiographic observations might also be observed for the hemodynamic findings. Normal values observed six hours after obtaining the abnormal chest radiograph might represent re-

Table 6: Summary of human studies concerning left ventricular performance in patients with subarachnoid hemorrhage.

\begin{tabular}{|c|c|c|c|c|c|}
\hline \multirow[t]{2}{*}{ Authors } & \multicolumn{3}{|c|}{ Type of study } & \multirow[t]{2}{*}{ No. of Patients } & \multirow[t]{2}{*}{ Findings } \\
\hline & CR/CS & RS & PS & & \\
\hline Pollick $1988^{30}$ & - & $\begin{array}{l}1 \text { index } \\
\text { case }\end{array}$ & $\begin{array}{c}12 \text { cases } \\
\text { studied } \\
\text { prospectively }\end{array}$ & 13 & $\begin{array}{l}\text { Abnormal wall motion in } 4 \text { patients } \\
\text { Presence of thrombus in } 2 \text { patients }\end{array}$ \\
\hline Davies $1991^{34}$ & - & & & 45 & Abnormal wall motion in 4 patients \\
\hline Handlin $1993^{22}$ & $\mathrm{X}$ & - & - & 1 & Septal, apical, and lateral LV akinesis (LVEF 25\%) \\
\hline Kono $1994^{56}$ & - & $\mathrm{X}$ & - & 12 & $\begin{array}{l}\text { Abnormal wall motion in } 12 \text { patients } \\
\text { Group with ST-segment elevation had more hypokinesis at apex }\end{array}$ \\
\hline Mayer $1994^{25}$ & $\mathrm{X}$ & - & - & 5 & $\begin{array}{l}\text { Abnormal wall motion in } 5 \text { patients (LVEF } 16 \text { to } 35 \% \text { initially) } \\
\text { Presence of apical thrombus in } 2 \text { patients }\end{array}$ \\
\hline Pinto $1994^{57}$ & $\mathrm{X}$ & - & - & 1 & Anterolateral, septal, apical hypokinesis (LVEF 25\%) \\
\hline Mayer $1995^{32}$ & - & - & $\mathrm{X}$ & 57 & $\begin{array}{l}\text { Abnormal wall motion in } 5 \text { patients (moderate to severe LVEF } \\
\text { reduction). Presence of apical thrombus in } 2 \text { patients }\end{array}$ \\
\hline Mayer $1999^{31}$ & - & $\mathrm{X}$ & - & 72 & Abnormal wall motion in 9 patients \\
\hline Sakka $1999^{58}$ & $\mathrm{X}$ & - & - & 1 & Interventricular septum hypokinesis (LVEF 10\%-12\%) \\
\hline Yasu $1999^{59}$ & $\mathrm{X}$ & - & - & 1 & Anterolateral and inferior akinesis and apical hypokinesis (LVEF 54\%) \\
\hline Parekh $2000^{33}$ & - & - & $\mathrm{X}$ & 39 & Abnormal wall motion in 5 patients (LVEF $25 \%$ to $50 \%$ ) \\
\hline
\end{tabular}

Abbreviations: $L V=$ left ventricular; $L V E F=$ left ventricular ejection fraction; $C R=$ case report; $C S=$ case series; $R S=$ retrospective study; $P S=$ prospective study. 
normalization. In addition, PE could also be absent in patients with cardiac involvement. A prospective trial of consecutive patients with systematic and timely fashioned hemodynamic monitoring and 2D echocardiographic examination would provide a more accurate estimation of the incidence of systolic and diastolic dysfunction following SAH. Thus, further study is warranted to prospectively assess the incidence and mechanisms of $\mathrm{PE}$ and the importance of diastolic dysfunction in this condition.

\section{REFERENCES}

1. Ducker TB. Central nervous system pressure and pulmonary edema. A clinical study. Trans Am Neurol Assoc 1967; 92:225-227.

2. Fein IA, Rackow EC. Neurogenic pulmonary edema. Chest 1982; 81:318-320.

3. Colice GL. Neurogenic pulmonary edema. Clin Chest Med 1985; 6:473-489.

4. Touho H, Karasawa J, Shishido H, et al. Neurogenic pulmonary edema in the acute stage of hemorrhagic cerebrovascular disease. Neurosurgery 1989; 25:762-768.

5. Pender ES, Pollack CV, Jr. Neurogenic pulmonary edema: case reports and review. J Emerg Med 1992; 10:45-51.

6. Gomez CM, Palazzo MG. Pulmonary artery catheterization in anaesthesia and intensive care. Br J Anaesth 1998; 81:945-956.

7. Zwissler B, Rank N, Jaenicke U, et al. Selective pulmonary vasodilation by inhaled prostacyclin in a newborn with congenital heart disease and cardiopulmonary bypass. Anesthesiology 1995; 82:1512-1516.

8. Hache M, Denault AY, Belisle S, et al. Inhaled prostacyclin (PGI(2)) is an effective addition to the treatment of pulmonary hypertension and hypoxia in the operating room and intensive care unit. [L'inhalation de prostacycline (PGI(2)) est un traitement complémentaire efficace de l'hypertension pulmonaire et de l'hypoxie observées en salle d'opération et à l'unite des soins intensifs]. Can J Anaesth 2001; 48:924-929.

9. Clements FM, de Bruijn NP. Perioperative evaluation of regional wall motion by transesophageal two- dimensional echocardiography. Anesth Analg 1987; 66:249-261.

10. Urbanowicz JH, Shaaban MJ, Cohen NH, et al. Comparison of transesophageal echocardiographic and scintigraphic estimates of left ventricular end-diastolic volume index and ejection fraction in patients following coronary artery bypass grafting. Anesthesiology 1990; 72:607-612.

11. Brutsaert DL, Sys SU, Gillebert TC. Diastolic failure: pathophysiology and therapeutic implications. J Am Coll Cardiol 1993; 22:318-325.

12. Rakowski $\mathrm{H}$, Appleton $\mathrm{C}$, Chan $\mathrm{KL}$, et al. Canadian consensus recommendations for the measurement and reporting of diastolic dysfunction by echocardiography: from the Investigators of Consensus on Diastolic Dysfunction by Echocardiography. J Am Soc Echocardiogr 1996; 9:736-760.

13. Felman AH. Neurogenic pulmonary edema. Observations in 6 patients. Am J Roentgenol Radium Ther Nucl Med 1971; 112:393-396.

14. Wray NP, Nicotra MB. Pathogenesis of neurogenic pulmonary edema. Am Rev Respir Dis 1978; 118:783-786.

15. Carlson RW, Schaeffer RC, Jr, Michaels SG, Weil MH. Pulmonary edema following intracranial hemorrhage. Chest 1979; 75:731734.

16. Harari A, Rapin M, Regnier B, et al. Letter: Normal pulmonarycapillary pressures in the late phase of neurogenic pulmonary oedema. Lancet 1976; 1:494.

17. Malik AB. Mechanisms of neurogenic pulmonary edema. Circ Res 1985; 57:1-18.

18. Theodore J, Robin ED. Speculations on neurogenic pulmonary edema (NPE). Am Rev Respir Dis 1976; 113:405-411.

19. Malik AB. Pulmonary vascular response to increase in intracranial pressure: role of sympathetic mechanisms. J Appl Physiol 1977; 42:335-343.
20. Staub NC. The pathogenesis of pulmonary edema. Prog Cardiovasc Dis 1980; 23:53-80.

21. Warnell P. The cardiopulmonary complications of aneurysmal subarachnoid hemorrhage: current trends in management. Axone 1992; 14:24-28.

22. Handlin LR, Kindred LH, Beauchamp GD, et al. Reversible left ventricular dysfunction after subarachnoid hemorrhage. Am Heart J 1993; 126:235-240.

23. Raymer K, Choi P. Concurrent subarachnoid haemorrhage and myocardial injury. Can J Anaesth 1997; 44:515-519.

24. Greenhoot JH, Reichenbach DD. Cardiac injury and subarachnoid hemorrhage. A clinical, pathological, and physiological correlation. J Neurosurg 1969; 30:521-531.

25. Mayer SA, Fink ME, Homma S, et al. Cardiac injury associated with neurogenic pulmonary edema following subarachnoid hemorrhage. Neurology 1994; 44:815-820.

26. Graf CJ, Rossi NP. Catecholamine response to intracranial hypertension. J Neurosurg 1978; 49:862-868.

27. Kolin A, Norris JW. Myocardial damage from acute cerebral lesions. Stroke 1984; 15:990-993.

28. Hawkins WE, Clower BR. Myocardial damage after head trauma and simulated intracranial haemorrhage in mice: the role of the autonomic nervous system. Cardiovasc Res 1971; 5:524-529.

29. Weir BK. Pulmonary edema following fatal aneurysm rupture. J Neurosurg 1978; 49:502-507.

30. Pollick C, Cujec B, Parker S, Tator C. Left ventricular wall motion abnormalities in subarachnoid hemorrhage: an echocardiographic study. J Am Coll Cardiol 1988; 12:600-605.

31. Mayer SA, Lin J, Homma S, et al. Myocardial injury and left ventricular performance after subarachnoid hemorrhage. Stroke 1999; 30:780-786.

32. Mayer SA, LiMandri G, Sherman D, et al. Electrocardiographic markers of abnormal left ventricular wall motion in acute subarachnoid hemorrhage. J Neurosurg 1995; 83:889-896.

33. Parekh N, Venkatesh B, Cross D, et al. Cardiac troponin I predicts myocardial dysfunction in aneurysmal subarachnoid hemorrhage. J Am Coll Cardiol 2000; 36:1328-1335.

34. Davies KR, Gelb AW, Manninen PH, et al. Cardiac function in aneurysmal subarachnoid haemorrhage: a study of electrocardiographic and echocardiographic abnormalities. Br J Anaesth 1991; 67:58-63.

35. Costachescu T, Denault AY, Guimond JG, et al. The hemodynamically unstable patient in the intensive care unit: hemodynamic vs. transesophageal echocardiographic monitoring. Crit Care Med 2002; 30:1214-1223.

36. Vasan RS, Benjamin EJ. Diastolic heart failure-no time to relax. N Engl J Med 2001; 344:56-59.

37. Vasan RS, Larson MG, Benjamin EJ, et al. Congestive heart failure in subjects with normal versus reduced left ventricular ejection fraction: prevalence and mortality in a population-based cohort. J Am Coll Cardiol 1999; 33:1948-1955.

38. Vasan RS, Benjamin EJ, Levy D. Prevalence, clinical features and prognosis of diastolic heart failure: an epidemiologic perspective. J Am Coll Cardiol 1995; 26:1565-1574.

39. Pinamonti B, Di Lenarda A, Sinagra G, Camerini F. Restrictive left ventricular filling pattern in dilated cardiomyopathy assessed by Doppler echocardiography: clinical, echocardiographic and hemodynamic correlations and prognostic implications. Heart Muscle Disease Study Group. J Am Coll Cardiol 1993; 22:808-815.

40. Rihal CS, Nishimura RA, Hatle LK, et al. Systolic and diastolic dysfunction in patients with clinical diagnosis of dilated cardiomyopathy. Relation to symptoms and prognosis. Circulation 1994; 90:2772-2779.

41. Giannuzzi P, Temporelli PL, Bosimini E, et al. Independent and incremental prognostic value of Doppler-derived mitral deceleration time of early filling in both symptomatic and asymptomatic patients with left ventricular dysfunction. J Am Coll Cardiol 1996; 28:383-390.

42. Pinamonti B, Zecchin M, Di Lenarda A, et al. Persistence of restrictive left ventricular filling pattern in dilated cardiomyopathy: an ominous prognostic sign. J Am Coll Cardiol 1997; 29:604-612. 
43. Sun JP, James KB, Yang XS, et al. Comparison of mortality rates and progression of left ventricular dysfunction in patients with idiopathic dilated cardiomyopathy and dilated versus nondilated right ventricular cavities. Am J Cardiol 1997; 80:1583-1587.

44. Redfield MM, Jacobsen SJ, Burnett JC, Jr, et al. Burden of systolic and diastolic ventricular dysfunction in the community: appreciating the scope of the heart failure epidemic. JAMA 2003; 289:194-202.

45. Sandham JD, Hull RD, Brant RF, et al. A randomized, controlled trial of the use of pulmonary-artery catheters in high-risk surgical patients. N Engl J Med 2003; 348:5-14.

46. Ducker TB. Increased intracranial pressure and pulmonary edema. 1. Clinical study of 11 patients. J Neurosurg 1968; 28:112-117.

47. Ciongoli AK, Poser CM. Pulmonary edema secondary to subarachnoid hemorrhage. Neurology 1972; 22:867-870.

48. Kosnik EJ, Paul SE, Rossel CW, Sayers MP. Central neurogenic pulmonary edema: with a review of its pathogenesis and treatment. Childs Brain 1977; 3:37-47.

49. Fein A, Grossman RF, Jones JG, et al. The value of edema fluid protein measurement in patients with pulmonary edema. Am J Med 1979; 67:32-38.

50. Eggleston CA. Clinical correlation of neurogenic pulmonary edema to increased intracranial pressure. J Neurosurg Nurs 1982; $14: 245-254$

51. Lagerkranser M, Pehrsson K, Sylven C. Neurogenic pulmonary oedema. A review of the pathophysiology with clinical and therapeutic implications. Acta Med Scand 1982; 122:267-271.

52. Melon E, Bonnet F, Lepresle E, et al. Altered capillary permeability in neurogenic pulmonary oedema. Intensive Care Med 1985; 11:323-325.

53. Schell AR, Shenoy MM, Friedman SA, Patel AR. Pulmonary edema associated with subarachnoid hemorrhage. Evidence for a cardiogenic origin. Arch Intern Med 1987; 147:591-592.

54. Deehan SC, Grant IS. Haemodynamic changes in neurogenic pulmonary oedema: effect of dobutamine. Intensive Care Med 1996; 22:672-676.

55. Smith WS, Matthay MA. Evidence for a hydrostatic mechanism in human neurogenic pulmonary edema. Chest 1997;111:1326-1333.

56. Kono $\mathrm{T}$, Morita $\mathrm{H}$, Kuroiwa $\mathrm{T}$, et al. Left ventricular wall motion abnormalities in patients with subarachnoid hemorrhage: neurogenic stunned myocardium. J Am Coll Cardiol 1994; 4:636-640.

57. Pinto RJ, Goyal V, Sharma S, Bhagwati SN. Transient myocardial dysfunction in a patient with subarachnoid haemorrhage. Int $\mathrm{J}$ Cardiol 1994; 46:289-291.

58. Sakka SG, Huettemann E, Reinhart K. Acute left ventricular dysfunction and subarachnoid hemorrhage. J Neurosurg Anesthesiol 1999; 11:209-213.

59. Yasu T, Owa M, Omura N, et al. Transient ST elevation and left ventricular asynergy associated with normal coronary artery in aneurysmal subarachnoid hemorrhage. Chest 1993;103:1274-1275. 